\title{
Recorregut de recerca geològica i mineralògica per la comarca de I'Alcalatén: des de Vistabella del Maestrat cap Atzeneta del Maestrat i cap a les Useres
}

Josep Maria Mata-Perelló

Joaquim Sanz Balagué

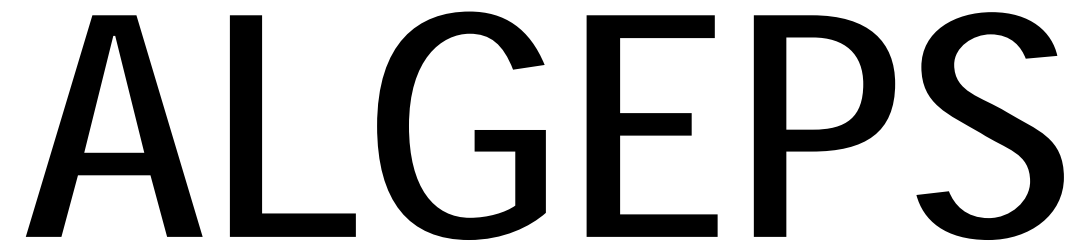

\section{REVISTA DE GEOLOGIA}

\section{n. 3}

JULIOL 2015 


\title{
RECORREGUT DE RECERCA GEOLÒGICA I MINERALÒGICA PER LA COMARCA DE L'ALCALATÉN: DES DE VISTABELLA DEL MAESTRAT CAP ATZENETA DEL MAESTRAT I CAP A LES USERES
}

\author{
Josep Maria Mata-Perelló \\ Museu de geologia Valentí Masachs, Escola Politècnica Superior d'Enginyeria de Manresa \\ (EPSEM), Universitat Politècnica de Catalunya · BarcelonaTech (UPC), 08272 Manresa, Spain
}

\section{Joaquim Sanz Balagué}

Departament d'Enginyeria Minera i Recursos Naturals (EMRN), Escola Politècnica Superior d'Enginyeria de Manresa (EPSEM), Universitat Politècnica de Catalunya - BarcelonaTech (UPC), 08272 Manresa, Spain

\section{Paraules clau: Patrimoni geològic i miner; Sistema ibèric; País Valencià}

\section{Resum}

Itinerari realitzat el dia 6 de desembre del 2014. Aquest itinerari es desenvoluparà íntegrament per una de les unitats geològiques que constitueixen el País Valencià: concretament per la que ocupa la major part de la seva superfície, per la Serralada Ibèrica (i dintre d'aquesta pels sectors denominats Muntanyam de Castelló. També, es podria incloure bona part del recorregut, dintre de la denominada Conca del Maestrat.

Així, l'itinerari discorrerà íntegrament per la zona també denominada del Maestrat, pels seus sectors corresponents a la Zona d'Enllaç entre les dues serralades anteriorment esmentades, de direccions: NE-SW (o NNE-SSW) i WNW-ESE (de vegades NW-SE), corresponents a les alineacions catalana i ibèrica, respectivament. Igualment, el recorregut s'inclou dintre d'aquesta zona, d'acord amb el treball de GUIMERÀ et altri (1992). En funció d'aquestes circumstàncies ens trobarem molts indrets amb clares interferències entre les dues direccions acabades d'esmentar; tot i que en aquestes interferències predominarà quasi sempre en aquesta zona, la direcció ibèrica. Aquest conjunt, es troba constituït majoritàriament per relleus mesozoics (fonamentalment pertanyents al Cretàcic i al Juràssic), de naturalesa calcària.

Per altra banda, el recorregut de l'itinerari transitarà per la gran comarca històrica del MaestratMaestrazgo, (coincident en bona part amb la unitat geològica del mateix nom). Tot i així, el recorregut de l'itinerari discorrerà per una sola comarca: la de l'Alcalatén (de la de Castelló). Així, el recorregut s'iniciarà per es immediacions de Vistabella del Maestrat, des d'on s'anirà cap a la població d’Atzeneta del Maestrat. Finalitzarà, per altra banda, prop de les Useres. 


\section{Objectius fonamentals}

Els objectius que es pretenen assolir, en aquest itinerari, es centraran, fonamentalment, en els següents aspectes:

1. Estudi dels materials dels afloraments mesozoics (de tots els períodes que el constitueixen, i en especial del Cretàcic), que constitueixen el Sistema Ibèric, dintre del sector anomenat "Muntanyam de Castelló" (RIBA et altri, 1976).

2. Observació de l'estructura del Sistema lbèric (i més concretament del que es troba situat dintre de l'esmentat sector "Muntanyam de Castelló" (RIBA et altri, 1976), que anirem trobant a bona part del recorregut de l'itinerari.

3. Estudi de les mineralitzacions situades al llarg del recorregut; $i$ en especial de les següents, d'acord amb el recorregut de l'itinerari:

3A) reconeixement de les mineralitzacions estratiformes de $\mathrm{Pb}-\mathrm{Zn}$, que trobarem al terme de Vistabella del Maestrat. Com al cas anterior, es troben situades entre els afloraments mesozoics del Cretàcic

3B) reconeixement de les mineralitzacions evaporítiques de caràcter guixós que trobarem al terme de Vistabella del Maestrat, entre els materials Triàsics del Keuper

3C) estudi de les mineralitzacions ferruginoses de rebliment de cavitats d'origen kàrstic, que trobarem als termes de les Useres i d'Atzeneta del Maestrat. Es localitzen entre els afloraments mesozoics del Cretàcic.

4. Observació de les diverses explotacions, situades al llarg del recorregut de l'itinerari. Entre aquestes, farem esment de les explotacions relacionades amb les mineralitzacions esmentades dintre de l'apartat anterior.

5. Observació dels impactes produïts sobre el Medi Natural, com a conseqüència de les explotacions anteriors; i també, si s'escau de les restauracions dutes a terme.

6. Observació dels indrets relacionats amb el nostre Patrimoni Geològic i Miner (en concret dels diferents Punts d'Interès Geològic o PIG; i dels diferents Punts d'Interès Miner o PIM), que anirem trobant al llarg del present itinerari. 


\section{Antecedents}

Pel que fa al recorregut de l'itinerari, existeixen pocs antecedents bibliogràfics antics. Tot i així, cal fer esment d'uns treballs molt recents: MATA-PERELLÓ 2014), MATA-PERELLÓ i CARDONA GAVALDÀ (2005) així com MATA - PERELLÓ i MUNTANÉ GARCÍA (2004). En tots els casos es tracta d'itineraris marginals en relació al que ara presentem.

Pel que fa a l'estructura geològica de la zona per la qual discorre el recorregut de l'itinerari, ens referirem a dos treballs, sensiblement importants: a GUIMERÀ et altri (1992), i a RIBA et altri (1976). També cal fer esment de l'IGME (1973).

I, finalment, pel que fa a la descripció de les mineralitzacions, es referirem a un altres antecedents bibliogràfic mostres. Concretament dels treballs de: MATA-PERELLÓ (1991 i 1992), dedicats al inventari mineralògic de les dues comarques per les quals transitarà el recorregut d'aquest itinerari.

Tots aquests treballs, i d'altres, apareixeran ressenyats a l'apartat dedicat a la BIBLIOGRAFIA.

\section{Recorregut de l'itinerari}

El recorregut de l'itinerari discorrerà íntegrament per una de les comarques de la Regió de Castelló. Concretament per la de l'Alcalatén. Així, el recorregut s'iniciarà a la localitat de Vistabella del Maestrat, per on es faran diverses aturades.

Després, seguint la carretera autonòmica valenciana, el recorregut es dirigirà cap a la població d'Atzeneta del Maestrat, per on es farà una altra aturada des d'on s'anirà cap a les Useres, utilitzant ara la carretera CV - 165. Per les immediacions d'aquest darrer poble, es farà una aturada al paratge de les Ferreries. En aquest indret finalitzarà el recorregut d'aquest itinerari.

\section{Advertiments previs}

Com en altres recorreguts de RECERCA GEOLÒGICA I MINERALÒGICA ..., si es disposa del temps suficient, poden efectuar-se passant per totes les parades i filloles. En cas contrari, recomanem prescindir de les anomenades PARADES - CONDICIONALS.

També cal tenir en conte que una part del recorregut final de l'itinerari, es realitzarà per camins de terra, per la qual cosa caldrà prendre les degudes precaucions,

Cal tenir, com sempre, una cura molt especial de respecte a la natura, al llarg de tot el recorregut de l'itinerari, i també fora d'ell. 


\section{Descripció de l’itinerari}

Com sempre, s'estructurarà en una sèrie de PARADES, que veurem breument a continuació. En cada una de les parades, s'indicarà (entre parèntesi) el número del mapa topogràfic, a escala 1:50.000, on es troba l'aturada. En aquesta ocasió, les aturades es troben situades dintre dels següents fulls del Mapa Topogràfico a Escala 1:50.000 (editat per I'Instituto Geográfico y Catastral de España): 592 (o de Villahermosa del Río), 593 (o de Coves de Vinromà), $\mathbf{6 1 5}$ (o de l'Alcora) i 616-617 (o de Vilafamés). Així doncs, la relació ordenada de les aturades que constitueixen aquest itinerari és la següent:

\subsection{Parada 1. BARRANC DE LA MINA. CARRETERA DE VISTABELLA DEL MAESTRAT A ATZENETA, Km 30,050 (TRENCALL DEL CAMÍ DE LA MINA), (terme municipal de Vistabella del Maestrat, comarca de l'Alcalatén). (Full 592).}

El recorregut d'aquest itinerari el començarem a la població de Vistabella del Maestrat. Des del poble, cal sortir per la carretera autonòmica valenciana, la CV - 170. En arribar a la corba de les immediacions del Km 30'050, caldrà agafar el camí que surt per la dreta, des de la mateixa corba. Després caldrà fer un recorregut proper a $1 \mathrm{Km}$, en arribar al barranc de la mina. Aquí caldrà agafar-lo, arribant finalment a la mina, on farem una aturada, després d'un recorregut proper als $5 \mathrm{Km}$, des de la parada anterior.

En aquest recorregut, hem continuat trobat els materials carbonatats del Cretàcic Inferior, sobre el que s'assenta la població de Vistabella. Aquests són els materials que apareixen a l'indret de I'aturada. Per d'altra banda, en aquest lloc hi ha una antiga mina, actualment aturada (i en bona part enrunada). Es fan força paleses les antigues instal-lacions, amb els plans inclinats $i$ alguns edificis, situats a banda i banda del torrent.

La mina es relaciona amb unes mineralitzacions estratiformes de $P b-Z n$, situades entre els nivells carbonatats cretàcics. Entre els minerals es troben els següents: entre els de plom, la GALENA (poc abundant); i entre els de zinc I'ESFALERITA (terrosa) i la SMITHSONITA (molt terrosa, en forma de CALAMINA).

També hi són presents altres minerals com els següents: GOETHITA (terrosa i limonítica), CALCITA i DOLOMITA.

\subsection{Parada 2 - CONDICIONAL. ALGEPSAR DEL MAS DE CLEDE . (Terme municipal de Vistabella del Maestrat, comarca de l'Alcalatén). (Full 592).}

Després de realitzar la parada anterior, cal retornar a la carretera CV - 170, per tal de continuar el recorregut cap al poble d'Atzeneta del Maestrat. Després d'un recorregut proper a $3 \mathrm{Km}$ es trobarà per l'esquerra un camí que es dirigeix cap al Mas de Clede, que ens caldrà agafar. En arribar-hi, trobarem l'algepsar. Així, des de la parada anterior haurem recorregut uns $4 \mathrm{Km}$, aproximadament.

En aquest recorregut, inicialment hem trobat afloraments dels nivells carbonatats que hem esmentat a la parada anterior. Després, haurem començat a trobar afloraments dels materials guixosos i argilosos del Triàsic Superior (del Keuper). Aquests són els materials que es troben a l'indret de la parada. 
Aquí hi afloren uns nivells guixosos, els quals pertanyen al Keuper. Aquests nivells han estat explotats en una guixera (o algepsar). Entre els minerals guixosos presents es troben els següents: ANHIDRITA, GUIX i HEMIHEDRITA. El segon és el mineral més abundant.

\subsection{Parada 3 - CONDICIONAL. CARRETERA DE VISTABELLA DEL MAESTRAT CAP ATZENETA DEL MAETRAT, Km 26, (terme municipal de Vistabella del Maestrat, comarca de l'Alcalatén). (Full 592).}

Després de fer la parada anterior, cal retornar a la carretera que ens va conduint cap a Vistabella del Maestrat. En arribar a les immediacions del Km 26, es pot fer si s'escau una nova aturada, a quasi $1 \mathrm{Km}$ de l'anterior.

Després d'efectuar la parada anterior, haurem continuat trobant a afloraments dels materials guixosos i argilosos del Triàsic Superior (del Keuper), en contacte per falla amb els materials carbonatats del Cretàcic Inferior, de l'Aptià, que són els que apareixen a l'indret de la present aturada.

Aquests materials es troben en aquest lloc intensament replegats, fent-se palesos uns interessants plecs a la vora de la carretera.

\subsection{Parada 4 - CONDICIONAL. TRENCALL CAP A BENAFIGOS, CARRETERA CV - 169, Km 0`3, (terme municipal de Vistabella del Maestrat, comarca de l'Alcalatén). (Full 592).}

Després de realitzar la parada anterior, cal fer un nou recorregut (proper a $1 \mathrm{Km}$ ) per la carretera CV - 170, fins arribar a les immediacions del Coll de Vidre, arribant a l'indret d'on surt la carretera que es dirigeix cap al poble de Benafigos. En trobar aquesta carretera, per I'esquerra, caldrà fer un petit recorregut a peu d'uns 300 metres i escaig, tot anant cap a l'esmentat poble de Benafigos. Així, des de la parada anterior, haurem recorregut poc menys de $1^{\prime} 5 \mathrm{Km}$, per tal d'arribar fins aquí..

En aquest recorregut, hem anat trobant els materials cretàcics carbonatats anteriorment esmentats als recorreguts anteriors. Aquests materials són els que es troben a l'indret de I'aturada. Per d'altra banda, en aquest indret es fan paleses diverses fractures que han trencat els materials carbonatats. Igualment es fa palesa una interessant estructura d'escurçament.

\subsection{Parada 5. CARRETERA CAP ATZENETA DEL MAESTRAT, COLL DEL VIDRE, (terme municipal d'Atzeneta, comarca de l'Alcalatén). (Full 592).}

Després de fer l'aturada anterior, cal tornar al Coll del Vidre, per tal de fer una parada en aquest indret. Així, des de la parada anterior, tot anant cap a Benafigos, haurem fet un desplaçament de poc menys de $0^{\prime} 3 \mathrm{Km}$.

Com als desplaçaments anteriors, en apropar-nos al Coll del Vidre, hem continuat trobant els afloraments mesozoics anteriorment esmentats. Aquests són els materials que apareixen a l'indret de l'aturada, on ara som. Aquests materials es troben intensament triturats, i es fan paleses nombroses falles per arreu, com succeeix a l'indret de l'aturada.

Ens trobem a una zona de clara interferència entre les estructures de "direcció catalana" i les de "direcció Ibèrica"; es a dir: entre els arrumbaments NNE - SSW i els de direcció WNW ESE, respectivament. 


\subsection{Parada 6 - CONDICIONAL. CARRETERA DE VISTABELLA DEL MAESTRAT CAP ATZENETA DEL MAESTRAT (CV - 170), Km. 23'8, (terme municipal d'Atzeneta, comarca de l'Alcalatén). (Full 592).}

Després de fer l'aturada anterior cal continuar per la carretera, apropant-nos cap a la població d'Atzeneta del Maestrat. En arribar a les immediacions del $\mathrm{Km} \mathrm{23} 8$ caldrà fer una nova aturada, a quasi 1'5 $\mathrm{Km}$ de l'anterior, aproximadament

En aquest recorregut, hem tornat a tallar els materials carbonatats ja esmentats a les parades anteriors. Aquests pertanyen en la seva major part al Cretàcic Inferior, a l'Aptià.

Per altra banda, sovint es fan palesos uns aflorament de glacis quaternaris que cobreixen als materials anteriors. Un d'aquests és el que apareix a l'indret de l'aturada, i es caracteritza per tenir un elevat contingut en fragments detrítics de composició carbonatada, procedents de l'erosió dels materials mesozoics anteriorment esmentats.

\subsection{Parada 6. CARRETERA CAP ATZENETA DEL MAESTRAT, Km. 23, (terme municipal d'Atzeneta, comarca de l'Alcalatén). (Full 592).}

Després de fer la parada anterior, cal fer un nou recorregut per la carretera CV - 170, anant sempre en direcció cap el proper poble d'Atzeneta del Maestrat. En arribar a les immediacions del $\mathrm{Km} \mathrm{23,} \mathrm{cal} \mathrm{fer} \mathrm{una} \mathrm{nova} \mathrm{aturada,} \mathrm{a} \mathrm{poc} \mathrm{menys} \mathrm{de} 1 \mathrm{Km}$ de la parada realitzada amb anterioritat.

En aquest recorregut, hem anat trobant els materials calcaris mesozoics ja esmentats a les parades anteriors. Aquests, en bona part pertanyen al Cretàcic. Tot i així, també trobarem afloraments carbonatats del Juràssic. Cal dir que aquests materials es troben molt replegats $i$ fracturats. Així, precisament en aquest lloc es fa clarament palesa una d'aquestes fractures, fent-se molt evident una falla entre els nivells carbonatats.

\subsection{Parada 7 - CONDICIONAL. MINES DE FERRO DEL RACÓ, CAMÍ A LES FERRERIES I A LES USERES, (terme municipal de les Useres, comarca de l'Alcalatén). (Full 592).}

Després de fer l'aturada anterior, cal continuar el recorregut per la carretera C - 170, amb la intenció d'arribar al poble d'Atzeneta del Maestrat. Després de sobrepassar el poble, cal seguir momentàniament per la carretera que es dirigeix cap a la Vall d'Alba, la mateixa CV 170. A uns 1,5-2 Km després de sobrepassar el poble, cal agafar un trencall per la dreta, que es dirigeix cap al Sud, cap a les Ferreries. En uns $2 \mathrm{Km}$, arribarem al Racó, per on farem aquesta aturada. Tot i així, aquest camí no es troba en gaire bones condicions, i possiblement és millor no agafar-lo, obviant l'aturada. Així, des de la parada anterior, haurem realitzat un recorregut molt proper als $14 \mathrm{Km}$.

En aquest llarg recorregut, $s^{\prime}$ han anat tallant els materials mesozoics ja esmentats a la parada anterior. Aquests materials són carbonatats, eminentment calcaris.

En aquest indret, hi ha unes antigues explotacions de ferro, similars a les de la parada següent. Tot i així, en aquest indret es troben les restes dels edificis de les mines, encara que totalment enrunats. 


\subsection{Parada 8. MINES DE FERRO DE LES FERRERIES, (terme municipal de les Useres, comarca de l’Alcalatén). (Full 593).}

Després de fer l'aturada anterior, cal continuar pel camí de terra, des del qual en uns $1^{\prime} 5-2$ $\mathrm{Km}$, es pot arribar a l'indret de les Ferreries. Tot i així, cal recordar aquest camí no es troba en gaire bones condicions, i possiblement és millor fer un altre recorregut, per tal d'arribar a aquestes antigues explotacions mineres. Així, el millor que cal fer es retornar des de la parada anterior a Atzeneta del Maestrat, per tal de continuar després per la carretera CV - 165, anant cap el poble de Les Useres. Després, (cap a les immediacions del $\mathrm{Km} \mathrm{3,3}$ de la carretera, a uns $6 \mathrm{Km}$ del primer poble) cal agafar un camí de terra que se'n va cap al Est (i cap a I'ESE). Aquest, ens durà en uns $3 \mathrm{Km}$ a les antigues Mines de Ferro de les Ferreries, per on farem la present aturada. Així haurem efectuat un recorregut proper als 10 - $11 \mathrm{Km}$ des de la parada anterior, per tal d'arribar fins aquí.

En aquest recorregut, inicialment hem anat trobant afloraments dels terrenys carbonatats de la Serra de les Useres, on ara estem situats. Així, haurem vist afloraments de les calcàries de I'Aptià, dels gresos i argiles de l'Albià i també calcàries del Cenomanià. Aquests són els materials que apareixen a l'indret de la present aturada.

En aquest indret hi ha les restes d'unes importants mines de ferro. Les restes consisteixen en una sèrie d'explotacions a "cel obert", (quasi totalment cobertes de vegetació) i en les escombreres d'aquestes. Una d'aquestes explotacions es troba a la vora d'una cruïlla de camins, $d^{\prime}$ on neixen els d'Atzeneta i les Useres. Les mines es relacionen amb mineralitzacions ferruginoses de rebliment de cavitats d'origen kàrstic. Aquestes es troben entre les calcàries mesozoiques del Cretàcic que hem esmentat anteriorment, de la Serra de les Useres. (fotografia 1).

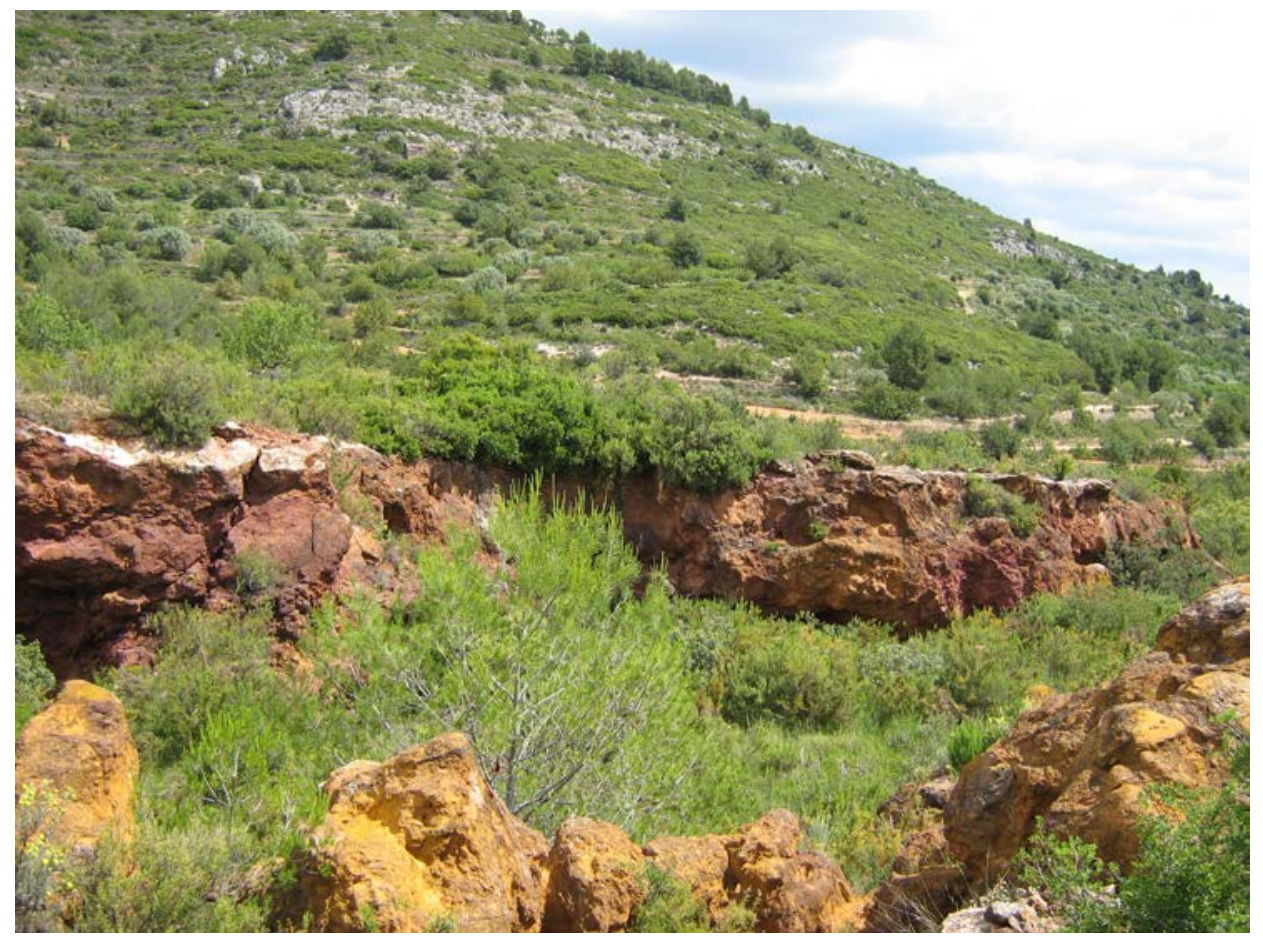

Fotografia 1. Mines de ferro de les Ferreries 
Entre els minerals presents, cal fer esment de la GOETHITA (molt terrosa i limonítica) i de I'HEMATITES (també molt terrós). Amb els es troben altres minerals com la LEPIDOCROCITA (poc abundant, molt semblant al primer mineral esmentat), la PIROLUSITA (terrosa), la CALCITA (força abundant) i la DOLOMITA.

\subsection{Parada 9. IMMEDIACIONS DE LA RAMBLA DE LA VIDUA, (termes municipals de les Useres i de la Vall d'Alba, comarques de I'Alcalatén i de la Plana Alta). (Full 616).}

Després de fer l'aturada anterior, cal continuar el recorregut per la carretera CV - 165, amb la finalitat d'arribar al poble de Les Useres. Després, des d'aquí, ens cal seguir per la carretera CV 159 (que condueix cap a la Vall d'Alba).. En arribar al pont sobre la Rambla de la Viuda, ens caldrà fer una nova aturada, a uns $7 \mathrm{Km}$ de les Useres i a uns 12 de la parada anterior, aproximadament.

En aquest recorregut, hem anat trobant afloraments dels materials carbonatats cretàcics de I'Aptià. Després, s' hauran fet palesos uns afloraments dels materials cenozoics del Miocè i del Pleistocè - Holocè que reblen la Depressió de la Vall d'Alba - Albocàsser, on ens trobem sara situats. Aquesta, és una depressió estructural de direcció catalana.

En aquest indret ens trobem sobre la Rambla de la Vídua. Es tracta d'un curs d'aigua típicament mediterrani, amb avingudes torrencials de caràcter estacional. Així, en observar els materials arrossegats per l'aigua, es pot veure el marcat caràcter heteromètric d'aquests materials, amb dimensions que oscil.len entre els $70-80 \mathrm{~cm}$ i el $10 \mathrm{~cm}$ de potència. Per d'altra banda, es pot veure el caràcter eminentment carbonatat d'aquests materials. En efecte, l'esmentada ha travessat els terrenys cretàcics i juràssics, els quals són eminentment carbonatats; i els sediments arrossegats procedeixen d'aquests terrenys acabats d'esmentar.

En aquest indret finalitza el recorregut.

\subsection{Bibliografia emprada}

GUIMERÀ, J. et altri (1992).- Geologia (II), Història Natural dels Països Catalans, Vol. 2, 547 pàg. Enciclopèdia Catalana, S.A.. Barcelona.

IGME (1973).- Mapa Geológico de España, a escala 1:50.000. Segona sèrie. Full i explicaciö $\mathrm{n}^{\mathrm{a}}$ 616 (Vilafamés). Inst. Geol. Mine. España. Minist. Indústria. Madrid.

MATA-PERELLÓ, J.M. (1991).- Inventari de Mineralitzacions i de Minerals del País Valencià. Col.lecció Informe, 546 pag. Manresa.

MATA-PERELLÓ, J.M. (2014).- Recorregut de recerca geològica i mineralògica per la comarca de I'Alcalatén: des de Llucena a les Useres, Atzeneta i a Vistabella del Maestrat. Inèdit. 12 pàgines. Manresa.

MATA-PERELLÓ, J.M. (1992).- Síntesi General de les Mineralitzacions de la Regió de Castelló. revista Algeps, $\mathrm{n}^{\circ} .7,35$ pàg. Manresa. 
MATA-PERELLÓ, J.M. i CARDONA GAVALDÀ, V. (2005).- Recorregut de recerca geològica i mineralògica per les comarques de la Plana Alta i l'Alcalatén: des de les Useres i Atzeneta a Vistabella del Maestrat. Inèdit. 12 pàgines. Manresa.

MATA-PERELLÓ, J.M. i MONTANÉ GARCÍA, P. (2004).- Recorregut de recerca geològica i mineralògica per les comarques de la Plana Alta, l'Alcalatén i I'Alt Maestrat: des de la Vall d’Alba i Atzeneta a Vistabella del Maestrat i a Vilafranca del Cid. Inèdit. 14 pag. Manresa.

RIBA ARDERIU, O. et altri (1976).- Geografia Física dels Països Catalans. Edit Ketres, 205 pàg. Barcelona. 